\title{
O Curso de Medicina e as Comissões Coorde- nadoras da Graduação na Faculdade de Medi- cina de Ribeirão Preto: Uma retrospectiva
}

\author{
Elisabeth Dovichi Magrini ${ }^{1} \&$ Roberto Martinez ${ }^{2}$ \\ 'Secretária da Comissão de Graduação. ${ }^{2}$ Presidente da Comissão de Graduação. Faculdade de Medicina de Ribeirão Preto - USP
}

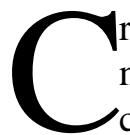
riada em 1952, a Faculdade de Medicina de Ribeirão Preto teve seu papel para com o ensino definido no Decreto $\mathrm{n}^{\circ}$. 37.077, publicado em 8 de agosto de 1960, referente ao regulamento da instituição. Entre outras finalidades, dispõe que deve "ministrar, desenvolver e aperfeiçoar o ensino das Ciências Médicas", além de "formar especialistas nas diversas disciplinas que constituem o ensino médico". Grande aliado do ensino de alto nível, que distinguiu a FMRP-USP desde os primeiros anos, foi a adoção por Zeferino Vaz, o primeiro diretor, do regime de trabalho de tempo integral para todos os professores, de áreas básicas ou clínicas ${ }^{(1)}$. A estrutura curricular original do curso da FMRP, aprovada em 1952 pelo Conselho Universitário da USP (CO), tinha 32 disciplinas, além de cinco facultativas. O $6^{\circ}$ ano permitia ao aluno as opções clínica ou cirúrgica. Tinha, como objetivo, o ensino integrado e cientificamente embasado da Medicina, considerando-se também os aspectos psicossociais da doença ${ }^{(2)}$. A primeira reforma do curso médico aconteceu em 1957, quando o CO aprovou uma solicitação do Diretor Zeferino Vaz para implantar uma nova seriação de cadeiras da FMRP, "para tornar o ensino mais lógico e condizente com o preparo dos alunos". A opção clínica ou cirúrgica no $6^{\circ}$ ano, foi mantida, surpreendendo o relator do processo, Prof. A. L. Ayrosa Galvão, que comentou a "novidade da especialização precoce, somente admissível em escolas de alto padrão, como a FMRP".
Entre 1959 e 1960, cinco comissões de professores designados pelo Diretor trabalharam consecutivamente, no sentido de estudar o entrosamento das disciplinas, fazer a análise crítica, propor uma reforma do currículo e efetivar as alterações sugeridas ${ }^{(3)}$. Destaca-se o relatório elaborado pela comissão composta pelos Professores Hélio Lourenço de Oliveira, Jorge Armbrust de Lima Figueiredo e Miguel Rolando Covian, no qual era criticada a autonomia e a falta de integração dos departamentos em relação ao ensino, e recomendava-se que, desde o $1^{\circ}$ ano, os alunos aprendessem conhecimentos científicos relacionados com a prática médica, dentro de uma seqüência coerente de disciplinas. A mudança curricular proposta incluía a aproximação temporal da aquisição de alguns conhecimentos básicos com a dos clínicos correspondentes e a transformação das disciplinas do $6^{\circ}$ ano em estágios de prática médica. $\mathrm{O}$ aprendizado deveria ser complementado com cursos extracurriculares, oferecidos por todos os departamentos e organizados na forma de seminários, trabalhos práticos e revisões bibliográficas. As modificações não foram aceitas por todos os docentes, tendo o Professor Rui Ferreira Santos protestado contra a "reforma radical" do curso, argumentando, entre outras razões, que a Faculdade de Medicina já havia formado três turmas de bons médicos. A reforma do currículo foi implantada na primeira metade da década de 60 e teve a participação da Comissão de Ensino, dirigida pelo Professor Miguel Rolando Covian. As opções de Inter- 
nato Clínico ou Cirúrgico desaparecem, substituídas por Internato Único, composto de estágio rotatório 32 semanas e estágio optativo - 16 semanas. A carga horária total era de aproximadamente $6.500 \mathrm{~h}$, mais plantões noturnos no Hospital das Clínicas da FMRPUSP e na Santa Casa de Ribeirão Preto. Em 1965, uma importante alteração da estrutura curricular foi efetuada, no ano inicial do curso, introduzindo-se disciplinas não convencionais para a época, como Genética, Matemática Aplicada à Biologia e Estatística ${ }^{(3)}$. Ciências Biológicas, um novo curso de graduação da FMRP-USP, era iniciado no mesmo ano.

Em 1970, a Comissão de Ensino da FMRPUSP, presidida, então, pelo Professor Gyorgy Böhm, apresentou uma nova estrutura curricular do curso que se iniciaria no ano seguinte. A comissão reconhecia que a estrutura não era a ideal, mas atendia à deliberação da Câmara de Graduação da USP sobre a hierarquização e semestralidade das disciplinas ${ }^{(4)}$. Em 1971, por meio da Portaria GR 1.380, a USP estabeleceu normas sobre atividades didáticas, incluindo a coordenação delas e a organização das disciplinas. Com base no Artigo 22 daquela portaria, a Congregação da FMRPUSP, em maio de 1971, constituiu a Comissão Coordenadora de Ensino (CCE), composta por docentes e representantes discentes. Foram coordenadores, na década de 70, os Professores José Eduardo Dutra de Oliveira, José Antunes Rodrigues e José Romano Santoro, seguindo-se o Professor Jarbas Leite Nogueira, no início da década de 80 . As sucessivas comissões do período preocuparam-se em definir os objetivos do curso médico, com formas de avaliação dos alunos e com a própria estrutura do curso. Um ofício da CCE ao Diretor, com data de 06/06/1975, mencionava que as alterações curriculares, propostas nos últimos cinco anos, tinham a finalidade de compor, de maneira lógica, um curso com dois anos de ciclo básico, três de aplicação e um de internato rotatório. Alertava, também, que a referida escola ainda não conseguira definir o tipo de médico que desejava formar, ainda que os docentes sempre orientassem no sentido de formação de um médico generalista, e que faltava integração em virtude do ensino continuar sob a responsabilidade de departamentos. Propunha a criação de um Núcleo de Tecnologia Educacional, que planejaria e coordenaria todo o ensino de graduação da FMRP-USP e as ações para uniformizar programas, aprimorar disciplinas e avaliar o ensino ${ }^{(5)}$. Entre as alterações efetivamente praticadas no currículo do curso de Medicina, na época referida, sobressaem a extinção dos estágios optativos do último ano e a multiplicação de disciplinas no curso clínico, várias delas por desdobramento de outras, denominadas Clínica Médica, Clínica Cirúrgica e Patologia. As especialidades médicas estavam sendo introduzidas no curso de Medicina da FMRP-USP, a pedido dos departamentos, fazendo com que o total de disciplinas passasse, de 38, em 1962, e 42, em 1972, para 68, em 1982.

Na segunda metade da década de 70, a CCE participou do estudo e planejamento de um Ambulatório Multidisciplinar, na nova sede do Hospital das Clínicas da FMRP-USP, para estágio de prática profissionalizante, não especializada, de internos do curso médico. Outra expansão muito significativa para o aprendizado de Medicina Comunitária, para a qual a CCE deu o aval, em 1977, foi a operacionalização pela Faculdade de um Centro de Saúde-Escola no Município de Ribeirão Preto. Apesar do reconhecimento da importância do ensino extra-hospitalar, a ampliação de ambulatórios e enfermarias gerais, no Hospital das Clínicas, ativado em 1977-1978, e a instalação de uma Unidade de Emergência, no antigo prédio do hospital, foram os pilares do ensino prático de Medicina nos 20 anos seguintes $^{(6)}$.

Em 1980, a FMRP-USP sediou o XX Congresso Brasileiro de Educação Médica, que teve a colaboração do Professor Cláudio Roberto Carvalho Rodrigues, membro da CCE e que foi eleito coordenador da comissão em 1983, permanecendo no posto até 1991. Foi realizado, também em 1980, o Seminário sobre Ensino Médico na FMRP-USP, que concluiu serem vantagens do curso a dedicação exclusiva dos docentes, a instituição responsabilizar-se tanto pelo ciclo básico, como pelo clínico, a ênfase inicial em Ciências Básicas e a adoção de Psicologia e de Medicina Preventiva desde a primeira etapa de implantação. Como pontos desfavoráveis, além da falta de integração vertical e horizontal, foi citada a prática insuficiente na comunidade e a pequena motivação do estudante, inclusive pelo não reconhecimento da aplicação dos conhecimentos básicos ${ }^{(7)}$. Os eventos de 1980 repercutiram na Congregação da FMRP-USP, que criou uma Comissão de Planejamento de Ensino (CPE), a qual esteve em atividade até 1983, definindo oito objetivos terminais do curso médico (a partir de dados coletados pela CCE em 1975) e chegando a sugerir uma nova estrutura curricular ${ }^{(7)}$. A CPE trabalhou independentemente da CCE, havendo poucas reuniões conjuntas para a conclusão das propostas. Esta última comissão, por outro lado, propiciou a ca- 
pacitação de docentes da FMRP-USP em cursos de metodologia pedagógica e didática, oferecidos pelo Núcleo / Centro Latino-Americano de Tecnologia do Ensino Superior (NUTES/CLATES). Contudo, o trabalho de maior relevância da CCE, presidida pelo Professor Cláudio R. C. Rodrigues, foram os estudos abrangentes sobre a estrutura curricular.

$\mathrm{Na}$ década de 80 , poucas disciplinas foram incorporadas ao curso médico, manifestando-se a CCE contrária a pedidos nesse sentido, ao constatar a falta de espaço no mosaico curricular, que se encontrava com a carga horária próximo da saturação total e com excessiva fragmentação do ensino ${ }^{(8)}$. A esse diagnóstico somaram-se a dificuldade de aceitação pelos Departamentos Clínicos da adoção das normas preconizadas, em 1983, pelo Conselho Federal de Educação para o Internato Médico, e a pequena disponibilidade de períodos livres para que alunos com dependência de disciplinas pudessem cursá-las. Tais fatos motivaram a CCE a defender uma revisão aprofundada da estrutura curricular, a partir de $1985^{(8)}$. Autorizada pela Congregação, em 1986, a CCE passou a fazer uma avaliação extensa do curso médico e de seus objetivos. Quanto a estes, analisou e validou a proposta anterior da CPE, havendo aprovação dos objetivos terminais do curso de Medicina da FMRP-USP na sessão da Congregação de 27 de março de $1987^{(9)}$. Outros projetos da CCE, definindo os objetivos intermediários e a confrontação e adequação das disciplinas aos propósitos do curso, foram apresentados à Congregação em junho do ano seguinte ${ }^{(10)}$. Com a aprovação do Novo Estatuto da Universidade de São Paulo, em 1988, a CCE passou a ser denominada de Comissão de Graduação (CG), sendo composta por sete docentes indicados pela Congregação e um representante discente, além dos respectivos suplentes, que também participam dos trabalhos. Em junho de 1991, o Professor José Antunes Rodrigues, presidente da CG, apresentou à Congregação as "Diretrizes Gerais dos Cursos de Graduação", as quais embasaram uma nova reforma curricular ${ }^{(11)}$. A realização pela CG, em 1992, do "Seminário sobre a estrutura curricular do Curso de Ciências Médicas" e do "I Fórum Paulista de Avaliação do Ensino Médico" contribuíram para o aperfeiçoamento e implementação do novo curso.

A reforma curricular, implantada a partir de 1993, foi a mais extensa praticada nos 50 anos de vida da FMRP-USP ${ }^{(12)}$. As 20 vagas do curso de Ciências Biológicas foram incorporadas às 80 vagas da Medi- cina, abrindo-se 100 vagas para Ciências Médicas, denominação dada aos dois anos iniciais do novo curso, após o qual os alunos optariam por Medicina ou Ciências Biológicas - Modalidade Médica, esta sem prejuízo de posterior graduação em Medicina. Várias disciplinas do ciclo básico e do ciclo clínico foram fundidas ou formaram conjuntos, buscando aprendizado integrado e propiciando espaço para a introdução de disciplinas de cunho humanístico, de iniciação na prática médica e optativas. O período do Internato foi duplicado, passando para quatro semestres letivos, compactando-se os ciclos básico e clínico do curso médico. O número total de disciplinas manteve-se próximo a 70 e a carga horária do curso alcançava cerca de 11.000 h, incluindo estágios e plantões. Na execução da reforma, a CG valeu-se do maior poder a ela atribuído, pelo Estatuto da USP de 1988, para planejar e organizar o ensino de graduação, assumindo maior controle sobre as disciplinas e reduzindo a departamentalização do curso médico.

Além da introdução gradativa das alterações curriculares, que se completaram em 1998, as comissões da década de 90, presididas pelos Professores William Alves do Prado e Luís Ernesto de Almeida Troncon, destacaram-se pelo conhecimento técnico do processo de ensino - aprendizagem - avaliação e pela produção científica relacionada com o ensino médico. A experiência local foi apresentada em congressos internacionais e publicada na forma de Simpósio - Ensino Médico na Graduação ${ }^{(13)}$ e de artigos em periódicos especializados e nesse trabalho, a CG teve a colaboração técnica de um órgão assessor que criara, em 1988-1989, o Centro de Apoio Educacional e Pedagógico. Um processo de avaliação continuada das disciplinas pelos alunos foi aperfeiçoado, tornando-se fonte permanente de dados para revisões curriculares.

O século XXI encontra o Professor Ricardo Brandt de Oliveira na presidência de uma CG totalmente renovada. Novos desafios são enfrentados: a estrutura curricular reformada requer ajustes, o Hospital das Clínicas da FMRP-USP e sua Unidade de Emergência, transformados em centros de alta complexidade e menos adequados ao ensino médico generalista, a criação de novos cursos na FMRP-USP. A expressiva ampliação do corpo discente e a diversificação da formação profissionalizante abrem uma nova era para o ensino de graduação na referida escola.

É perceptível, nesta breve narrativa, que, nos 50 anos de existência da FMRP-USP, houve uma con- 
tínua labuta e interesse por um ensino de graduação de qualidade. A gratificação a tal ideal veio com a primeira posição dentre as escolas médicas brasileiras, alcançada pela $46^{\mathrm{a}}$ Turma no Exame Nacional de Cursos, no ano do cinqüentenário. As sucessivas Comissões de Coordenação do Ensino de Graduação, lembram-se obrigatoriamente do trabalho dedicado de ex-membros, que não foram citados no texto, mas muito representaram para o sucesso e prestígio do ensino de Medicina na FMRP-USP.

\section{AGRADECIMENTOS}

Aos professores Maria de Lourdes Veronese Rodrigues e William Alves do Prado, ex-integrantes da Comissão de Graduação da FMRP-USP, pelas informações prestadas.

\section{REFERÊNCIAS BIBLIOGRÁFICAS}

1 - AZEREDO AP. Tempo integral, base do ensino universitário. Medicina - Revista do CARL e do HC da FMRP da USP, 8: 29-36, 1975.

2 - UNIVERSIDADE DE SÃO PAULO. FACULDADE DE MEDICINA DE RIBEIRÃO PRETO. Processo 64.1.67.17.8, Criação e instalação da FMRPUSP. FMRP, Ribeirão Preto, s.d.

3 - UNIVERSIDADE DE SÃO PAULO. FACULDADE DE MEDICINA DE RIBEIRÃO PRETO. Processo 444/64,, Estrutura curricular. FMRP, Ribeirão Preto, s.d. Vol. 1.
4 - UNIVERSIDADE DE SÃO PAULO. FACULDADE DE MEDICINA DE RIBEIRÃO PRETO. Processo 444/64, Estrutura curricular. FMRP, Ribeirão Preto, s. d. Vol. 2.

5 - UNIVERSIDADE DE SÃO PAULO. FACULDADE DE MEDICINA DE RIBEIRÃO PRETO. Processo 444/64, Estrutura curricular. FMRP, Ribeirão Preto, s.d. Vol.7.

6 - MARTINEZ R. O ensino das urgências em Clínica Médica. Medicina, Ribeirão Preto, 25: 349-350, 1992.

7 - UNIVERSIDADE DE SÃO PAULO. FACULDADE DE MEDICINA DE RIBEIRÃO PRETO. Processo 444/64, Estrutura curricular. FMRP, Ribeirão Preto, s.d. Vol. 9.

8 - UNIVERSIDADE DE SÃO PAULO. FACULDADE DE MEDICINA DE RIBEIRÃO PRETO. Processo 444/64, Estrutura curricular. FMRP, Ribeirão Preto, 1985. Vol. 14.

9 - AMORIN DS. As implicações do avanço científico-tecnológico na definição do perfil do médico. Medicina, Ribeirão Preto, 22: 144-149, 1989.

10 - UNIVERSIDADE DE SÃO PAULO. FACULDADE DE MEDICINA DE RIBEIRÃO PRETO. Processo 89.1.433.17.9. Estruturas curriculares do ano de 1990. FMRP, Ribeirão Preto, s.d.

11 - UNIVERSIDADE DE SÃO PAULO. FACULDADE DE MEDICINA DE RIBEIRÃO PRETO. CONGREGAÇÃO. Atas das reuniões, 1991, FMRP, Ribeirão Preto, 1991.

12 - PRADO W A . Desenvolvimento e implantação da nova estrutura curricular na Faculdade de Medicina de Ribeirão Preto: dificuldades e avanços. Medicina, Ribeirão Preto, 29: 373-382, 1992.

13 - TRONCON LEA. Ensino médico de graduação: em busca de maior qualidade. Medicina, Ribeirão Preto, 29: 365-371, 1996. 